\title{
PODE HAVER DEMOCRACIA SEM LIBERDADE?
}

\author{
CAN DEMOCRACY BE WITHOUT FREEDOM?
}

Rafael Navarro*

\section{RESUMO}

O artigo endossará a tese que trata a Democracia como governo pelo debate, mas será invertida a formulação clássica do Contratualismo. Ao invés de sermos obrigados a agir segundo alguma concepção de Vontade Geral ou com propostas imparciais que busquem o benefício mútuo, em uma sociedade o indivíduo está intitulado a agir de qualquer modo que não seja razoavelmente rejeitável. A concepção de Agamben de Ética como Forma-de-vida é assumida aqui como um modo para a efetivação da liberdade social. O que se propõe é uma Ética que trata o Direito como um conjunto de regras constitutivas em uma Democracia. E se a liberdade humana é vinculada à compreensão de regras, então é preciso uma concepção de semântica para se determinar o significado das regras. Portanto, outra premissa explicitamente assumida é a primazia da pragmática em relação à semântica. Porque dizer qual é o conteúdo de uma regra significa dizer como este conteúdo será usado como premissa em inferências e nas ações do sujeito. Assim, é defendido que o reconhecimento da autoridade de uma pessoa em uma Democracia é condição necessária para a liberdade social, sem a qual o Estado tornase mero dispositivo de dominação.

PALAVRAS-CHAVE: Democracia. Ética. Filosofia do Direito. Justiça. Liberdade.

\begin{abstract}
In this text the thesis of Democracy as goverment by discussion is endossed, but the classic formula of Contractualism is reversed. Instead of being obligated to act by some conception of General Will or only with impartial reasons that seek mutual benefits, in a society a individual is entitled to do anything that is not reasonable rejectable. Agamben's understand of Ethics as a Way-of-Life is assumed here as a tool for Social Freedom effectiveness. The goal is an Ethics that treat the Law as Constitutive Rules in a Democracy. And if the human freedom is vinculated to our understanding of rules, then a semantics account is needed to determinate the meaning of rules. Therefore, another premise is the primazy of pragmatics in relation with semantics. Because say what is the conent of a rule is to say how the rule is supposed to be understood to show up as a premise in some inference. In this way the recognition of the authority of a person in a Democracy is a necessary condition for Social Freedom. And without it the State became just an instrument of oppression.
\end{abstract}

KEYWORDS: Democracy. Ethics. Philosophy of Law. Justice. Freedom.

\footnotetext{
* Graduado em Filosofia e Doutor em Direito pela PUC Minas. E-mail: kendernavarro@gmail.com.
} 


\section{INTRODUÇÃO}

Aqui será sustentada a Liberdade como elemento fundamental da Justiça. Enquanto um modo de vida livre de anomias por conta da coerência normativa dependente de atitude do sujeito membro de uma sociedade, a Justiça encontra seu terreno mais fértil em uma Democracia compreendida como governo pelo debate. A proposta deste artigo parte do insight que inverte a formulação clássica do contratualismo. Ao invés de sermos obrigados a agir somente de um modo que possa ser universalmente endossado, em uma sociedade o indivíduo está intitulado a agir de qualquer modo que não seja razoavelmente rejeitável.

Essa inversão é produto do debate Ético em um âmbito no qual o discurso moral foi esvaziado exatamente por não conseguir se sustentar. Pois o discurso moral demanda uma adequação entre a ação e os valores substantivos determinados de uma dada comunidade ou tradição, e a exigência dessa adequação com padrão previamente estabelecido cria uma situação de anomia por meio da exclusão daqueles que possuam valores morais distintos do padrão comunitário. O discurso Ético, por outro lado, deve se validar a cada caso em sua singularidade apresentando razões próprias a cada agente. Enquanto a moral pleiteia validação transcendental, a Ética se constitui por meio da relação intersubjetiva entre pessoas interessadas. O valor moral deve ser um valor comum que a pessoa assume como "nosso valor comunitário"; já o valor ético demanda uma fundamentação apropriada e, portanto, só pode se dar como um valor próprio, presente, singular e intersubjetivo.

Valores éticos podem ser compreendidos por sua fundamentação. As razões de uma teoria ética devem poder responder: qual tipo de prática pode me propiciar um modo de vida no qual eu possa me beneficiar da sociedade na qual vivo? $\mathrm{O}$ argumento deste artigo busca defender que a resposta "uma prática que reduza injustiças" é mais apropriada na busca do bem social. Esta resposta demanda reconhecer que

se alguém tem o poder de fazer uma diferença que ele ou ela percebe que irá reduzir a injustiça no mundo, então aí está um argumento racional forte para fazer exatamente isso (sem precisar vestir isso tudo em termos de uma imaginada vantagem prudente em um hipotético exercício de cooperação). (SEN, 2009, p. 271). 


\section{UMA LEXICOGRAFIA DA MORAL E ÉTICA}

Será útil explicitar significados atribuídos a Moral e a Ética ${ }^{1}$ a fim esclarecer o emprego de tais termos neste texto. Moral, em seu étimo moris, indica costume ou hábito, e foi o termo latino usado para traduzir o grego éthos quando os pensadores romanos traduziram os textos filosóficos gregos. Assim, "a moral" escrita com minúscula, artigo definido feminino e denotando um substantivo, indica um conjunto de valores que permite inteligir qual é a atividade praticada. "Neste uso do termo, a moral é um sistema de conteúdos que reflete determinada forma de vida. Esse modo de vida não costuma coincidir totalmente com as convicções e os hábitos de todos e de cada um dos membros da sociedade tomados isoladamente." (CORTINA; MARTINEZ, 2013, p. 13-14).

É a moral asteca que faz da morte sacrificial de um indivíduo que tem o coração arrancado ainda pulsando um sacrifício e distingue essa morte da execução do fuzilado no paredão cubano e do genocídio do povo preto pobre cometido pela PM nas periferias brasileiras. Portanto, normalmente a moral influencia o ato perlocucionário de um agente qualquer ao delimitar um conteúdo semântico esperado de um interlocutor que faça parte de um dado grupo. Qualquer professor que saiba adaptar seu discurso sobre determinado conteúdo ao nível de conhecimento da turma que estudará com ele consegue compreender essa influência. Nessa concepção do termo "moral", ele se identifica com o conceito de "bem comum". E é esse sentido do termo que a tese defendida neste trabalho considera razoavelmente rejeitável como fundamento de uma Sociedade Democrática.

Isso por conta de um segundo significado do termo "moral". Este, também escrito com minúscula, artigo definido feminino e denotando um substantivo, indica um conjunto de valores pessoais e pode ser usado para fazer referência ao código de conduta pessoal de alguém. Nesse sentido do termo, moral designa sempre conteúdos concretos e pessoalmente assumidos. Segundo Cortina e Martinez, esses conteúdos são uma síntese de dois elementos:

\footnotetext{
A) o patrimônio moral do grupo social a que alguém pertence e

B) a própria elaboração pessoal com base no que alguém herdou do grupo; essa elaboração pessoal está condicionada por diferentes circunstâncias, tais como idade, condições socioeconômicas, biografia familiar, temperamento, habilidade para raciocinar corretamente, etc. (CORTINA; MARTINEZ, 2013, p. 14).
}

\footnotetext{
${ }^{1}$ As definições aqui apresentadas para o significado do termo "moral" constam em Ética, livro de Adela Cortina e Emílio Martinez (2013). Para o termo Ética eu aceito o significado apresentado no referido livro, mas considero que esta não é uma concepção suficientemente abrangente.
} 
Nesse segundo sentido, que é inerente à condição humana, a moral constitui as crenças com pretensão legitimadora da ontologia que condiciona o modo como o indivíduo lida com a realidade. Um indivíduo cuja moral determine que a raça humana foi criada de um modo binário dividido entre homens e mulheres não possui arcabouço semântico para compreender a importância das questões de gênero. Pois "uma assertiva, mesmo se verdadeira, não é assumida como expressão de conhecimento a menos que aquele que a proferir compreenda a declaração que está sendo feita" (BRANDOM, 1994, p. 214). A moral nesse sentido condiciona as possibilidades ilocucionárias de um agente. Assim, sem fundamentação Ética qualquer moral é razoavelmente rejeitável.

Fundamentação Ética se distingue de um terceiro sentido do termo "Moral", normalmente escrito com maiúscula referindo-se a uma ciência que trata do bem em geral e das ações humanas conforme marcadas pela bondade ou pela malícia. Porém "essa suposta 'ciência do bem em geral' a rigor não existe. O que existe é uma variedade de doutrinas morais ('moral católica', 'moral protestante', 'moral comunista', etc.) e uma disciplina filosófica, a filosofia Moral ou Ética” (CORTINA; MARTINEZ, 2013, p.15). E aqui há um ponto terminológico importante para os estudos jurídicos que ainda teimam no erro de se conceberem como doutrina. Pois as doutrinas morais são constituídas com a transmissão, de geração em geração, de tradições ancestrais acerca do bem e do mal (no Direito do lícito e ilícito) reportadas à autoridade de algum intérprete legítimo. Logo, tratar o pensamento jurídico democrático como doutrina é uma contradição em seus próprios termos.

\begin{abstract}
Assim, chamamos de "moral" [o] conjunto de princípios, normas, e valores que cada geração transmite à geração seguinte na confiança de que se trata de um bom legado de orientações sobre o modo de se comportar para viver uma vida boa e justa. E chamamos de "Ética" [a] disciplina filosófica que constitui uma reflexão de segunda ordem sobre os problemas morais. (CORTINA; MARTINEZ 2013, p. 20).
\end{abstract}

Para o sentido de Ética assumido aqui é atribuído uma função tripla:

1) esclarecer o que é a moral, quais são seus traços específicos; 2) fundamentar a moralidade, ou seja, procurar averiguar quais são as razões que conferem sentido ao esforço dos seres humanos de viver moralmente; e 3) aplicar aos diferentes âmbitos da vida social os resultados obtidos nas duas primeiras funções, de maneira que se adote nesses âmbitos sociais uma moral crítica (isto é, racionalmente fundamentada [ou Ética]), em vez de um código moral dogmaticamente imposto ou da ausência de referências morais. (CORTINA; MARTINEZ, 2013, p. 21). 
Se alguma moral, enquanto conjunto de valores de uma pessoa ou um grupo, só possa existir de uma forma opressora em relação a um dado grupo qualquer que se encontre em situação de desigualdade desvantajosa, então a doutrina Moral que sustenta aquela moral é razoavelmente rejeitável. O sentimento de capacidade de uma pessoa ou grupo pode ser presumido se se identifica uma base ontológica comum entre os agentes éticos.

\begin{abstract}
Encontrar uma base comum não é posterior à compreensão, mas uma condição para que ela ocorra... Uma criatura que não possa, em princípio, ser compreendida nos termos de nossas próprias crenças, valores e modos de comunicação, não é uma criatura que tem pensamentos radicalmente diferentes dos nossos, é uma criatura sem aquilo que chamamos de pensamentos. (DAVIDSON apud MACINTYRE, 1991, p. 276).
\end{abstract}

Assim, se a Moral se restringir a uma formação universal e pretensão de imparcialidade, ela acabará com a forma de vida de pessoas e grupos inteiros. Pois valores universais rejeitam todos aqueles que não são comuns ao padrão universal estabelecido, neste caso a doutrina Moral excludente. Esse é o delatado produto do fechamento operatório do Direito. Se se declara que somente um discurso racional deve operar o Direito, mas se exclui os modelos de racionalidade que não se adequem aos critérios da razão iluminista, então não pode haver compreensão. E sem compreensão a intersubjetividade, elemento fundamental da Ética, não pode se constituir. Portanto

Ética não é a vida que simplesmente se submete à lei moral, mas a que aceita, irrevogavelmente e sem reservas, pôr-se em jogo nos seus gestos. Mesmo correndo o risco de que, dessa maneira, venham a ser decididos, de uma vez por todas, a sua felicidade e a sua infelicidade. (AGAMBEN, 2007, p. 61).

\title{
2 O DIREITO DE SEGUIR REGRAS EM SOCIEDADE
}

Seguir uma regra é livremente pô-la em uso. Entretanto, a letra da lei não serve como fundamentação para a ação jurídica por não ser capaz de oferecer as bases para inferências materiais fortes. Por isso uma regra "não pode ter a forma da lei, mas, como regula, aproxima-se da própria forma da vida, que guia e orienta ('regula dicta quod recte ducit' diz uma etimologia de Isidoro)” (AGAMBEN, 2014, p. 57). A demanda de pôr a regra em uso livremente reconhece o insight de sermos obrigados não por regras, mas pela nossa concepção das regras. Afinal, "semântica responde à pragmática, e atribuições de conteúdo a explicações sobre uso" (BRANDOM, 1994, p. 188). 
Assim, podemos seguir a concepção de uma regra livremente, questionando incoerências que tal sujeição possa produzir em determinados casos concretos, ou nos comportar segundo uma doutrina moral que requer que a lei não seja questionada. Neste segundo caso se ignoraria que uma vida que se instituir em sua integralidade na forma de uma lei ou mera regularidade já não será verdadeiramente vida. Seguir uma regra eticamente só é possível como forma de vida.

Se "é comum a todos os significados de princípios o fato de ser o primeiro termo a partir do qual algo é ou é gerado ou é conhecido" (ARISTÓTELES, Met. V, 1013a 17 et seq.), então o Direito é o princípio de uma sociedade. Enquanto conjunto totalizante de regras constitutivas $^{2}$, o Direito determina que o indivíduo social não pode ser excluído, como acontece com a pessoa à margem de uma comunidade. "[As] normas chamadas constitutivas não prescrevem um ato determinado nem regulam um estado de coisas preexistente, mas fazem elas mesmas existir aquele ato ou estado de coisas." (AGAMBEN, 2014, p. 78). São tais regras constitutivas que distinguem uma sociedade de uma comunidade, e segui-las só é possível eticamente, ao invés da adequação Moral de um ato singular a um padrão valorativo determinado pelo bem comum.

Assim, fazer parte de uma sociedade constitui uma forma de vida democrática vinculada ao Direito. "Uma forma de vida seria, por conseguinte, o conjunto de regras constitutivas que a definem. [Mas] não se poderia dizer antes, e com a mesma verdade, que é a forma de vida [do cidadão] que cria suas regras?” (AGAMBEN, 2014, p. 79). Por isso não é o Direito ou a Moral que estabelece a forma de vida que as pessoas podem viver em uma sociedade, mas é a Ética, responsável por um bem apropriado, que dá vida ao Direito que "se trata de uma escritura em si inerte, que deve ser 'posta em uso' pela leitura" (AGAMBEN, 2014, p. 85). Pôr em uso significa profanar e restituir o Direito ao indivíduo membro da sociedade democrática e com isso conferir-lhe potência. Ao contrário do poder que conserva o padrão comportamental de uma comunidade, um Direito potente é capaz de fundamentar o dinamismo social composto pelo conjunto de ações sociais, que produzem e são produzidas por regras constitutivas de forma de vida.

Em sociedades complexas, o Direito é um sistema de regras constitutivas que intitula as pessoas a certos tipos de ações e práticas. "Frequentemente, quando um compromisso é atribuído a um interlocutor, por definição, intitulamento é atribuído também a este

\footnotetext{
${ }^{2}$ O exemplo de Wittgenstein (apud AGAMBEN, 2014, p. 78) é o do jogo de xadrez, cujas regras constituem o próprio jogo. "O bispo é a soma das regras pelas quais é movido."
} 
interlocutor.” (BRANDOM, 1994, p.177). Ora, um agente é responsável pelo fim estabelecido para sua ação e pelos meios empregados para alcançar esses fins. A ação será ética, ou seja, livre de anomia e atribuída singularmente a um agente normativamente coerente, se o fim for fundamentado por uma justificativa que não seja razoavelmente refutável. O agente será eticamente repreensível se os meios escolhidos não condizem com os fins ou se lhe for demonstrado que outros meios seriam mais adequados ao fim estabelecido. Afinal, escolher um fim para sua ação é escolher também os meios que levam até ele.

Compreender as demandas da justiça não é um exercício mais solitário do que qualquer outra disciplina humana. Quando tentamos conceber como devemos nos comportar, e quais tipos de sociedade devem ser compreendidas como patentemente injustas, temos motivos para ouvir e prestar atenção aos pontos de vista e sugestões dos outros, o que pode nos levar, ou não, a revisar algumas de nossas conclusões. (SEN, 2010, p. 88).

Dessa forma, sempre que o Direito se valer apenas de seus próprios recursos, a ação jurídica estará reproduzindo a situação anômala de uma patologia social. A atuação de um operador, de alguém que apenas exerce uma função em um sistema, é incapaz de se estabelecer como uma ação ética, pois não é singularizável em sua repetição desinteressada. E, exatamente por não poder ser ética, tal ação será repreensível. Agir apenas segundo máximas que possam ser universalizáveis não é um meio capaz de gerar o bem humano. A boa ação e a ação moral são duas coisas muito diferentes ${ }^{3}$.

Aceita-se neste texto a concepção de que a sociedade se organiza em um conjunto de instituições e que as pessoas são intituladas a agir em qualquer sistema institucional do qual façam parte. "Intitulamento é, a princípio, um status social que uma performance ou compromisso possui dentro de uma comunidade." (BRANDOM, 1994, p. 177). Porém, a tese de que as instituições se manifestam enquanto sistemas autopoiéticos regulados segundo suas próprias regras operatórias demanda que os indivíduos que operam os sistemas se reportem à autoridade cognitiva das razões dadas e pedidas pelas pessoas afetadas pela eficácia social do sistema. Afinal, “ações são distinguíveis de performances comportamentais geralmente por meio de sua responsabilidade para com o escrutínio e deliberação a respeito das responsabilidades inferencialmente articuladas em que elas incorrem e que elas quitam" (BRANDOM, 1994, p. 336). Negar isso implica assumir que o modelo de organização social moderno só é capaz de se manifestar como patologia social. Se um dado sistema ou

\footnotetext{
${ }^{3} \mathrm{Na}$ Introdução à Fundamentação da metafísica dos costumes, Kant faz questão de deixar esse ponto muito claro.
} 
instituição for concebido apenas como um conjunto de comportamentos de operadores anônimos, então não há nenhuma possibilidade de crítica coerente. Pois "é em virtude da capacidade de alguém em adotar atitudes deônticas práticas, em assumir ou tratar algo como possuidor de autoridade cognitiva, que alguém pode contar como se movendo no espaço de dar e pedir razões" (BRANDOM, 1994, p. 215). Por isso, sistemas como o Direito são regulados por meio da abertura simbólica que requer a um agente institucional se apropriar das razões oriundas de outros sistemas como premissas e finalidade pretendida de sua ação.

Portanto, somente se um sistema for concebido como constituído por pessoas singulares poderá ele ter qualquer pretensão de ser uma instituição ética.

\footnotetext{
Críticas morais se aplicam somente a criaturas racionais, pois apenas estas são capazes do tipo de autogoverno reflexivo em questão. Além disso, se aplicam a elas apenas a respeito de suas atitudes sensíveis a julgamento: isto é, aquelas atitudes que, em uma criatura racional, devem estar sob o controle da razão. (SCANLON, 1998, p. 272).
}

E em uma democracia, nenhuma outra área demanda mais o controle da razão do que a prática jurídica. A pretensão de legitimar a força coercitiva que lhe é inerente atribui uma obrigação normativa irrevogável ao Direito. Que o controle da razão seja um controle exercido pela razão, com a demanda de fundamentos intersubjetivamente consistentes e que não sejam razoavelmente rejeitáveis. Afinal "conhecimento objetivo necessita de variedade de opiniões" (FEYERABEND, 1993, p. 32). Mas também um controle da razão para que os vicários estatais não se fechem paroquialmente em razões que só eles podem conceber, já que "preconceitos são encontrados pelo contraste, não pela análise" (FEYERABEND, 1993, p. 22). A autoridade atribuída pelo Direito é exercida como modo de vida, não como juízo determinante segundo uma lei geral. Logo, quanto mais próximo da ação concreta e mais longe da formalidade, mais real é o Direito. Por isso, o intérprete legítimo do Direito em uma democracia é qualquer pessoa com a responsabilidade decorrente do compromisso de dar e pedir razões.

\section{O DILEMA MORAL DE SE SEGUIR REGRAS E A ESCOLHA ÉTICA DA FORMA DE VIDA}

Para Aristóteles a virtude, ou excelência, é identificada no comportamento de uma pessoa que se manifesta como uma regularidade. O homem virtuoso deve possuir a forma da 
virtude. Em Aristóteles uma virtude é definida por um hábito. Neste modelo, a razão que confere sentido à ação é determinada externamente ao agente, sendo avaliada como virtuosa ou não simplesmente por seu conteúdo perlocucionário. Assim, um indivíduo com o status normativo de sábio (um tutor, professor, mestre, vicário estatal...), já conhecendo as respostas possíveis dos dilemas Morais, qualifica o comportamento de um agente como correto ou incorreto, moral ou imoral. Se o agente que erra souber proferir a resposta certa, mesmo tendo agido incorretamente, pode-se atribuir a ele akrasia, uma fraqueza da vontade [boulesthai] ${ }^{4}$ que se deixou guiar pelas paixões ao invés de assumir o controle com a parte racional de sua mente. Portanto, para Aristóteles a pessoa virtuosa obedece à regra moral determinada pelo bem particular de cada coisa. Para o fundador do Liceu questões Éticas se reduzem a dilemas Morais propostos pelo conflito de vontades na vida pública.

Quando compreendido como mediador de conflitos entre vontades antagônicas, o Direito se apresenta em uma estrutura que dificilmente se desvincula de dilemas morais. Neste entendimento, um autor apresenta os fatos expressando uma vontade, o réu apresenta uma tese oposta explicitando uma vontade diversa da do autor, e o vicário estatal fica encarregado de solucionar o dilema moral decidindo sobre qual das duas teses apresentadas é a mais adequada para a situação e melhor para a comunidade. Assim, pela fórmula do famoso adágio "dê-me os fatos e eu lhe darei o Direito", a Justiça é uma dádiva do Estado ou da comunidade, retribuindo as partes com as sanções determinadas pela doutrina Moral que o vicário estatal usará para interpretar o Direito positivo.

O grande problema é que o Direito pensado nesses termos se impõe como regra com uma rigidez digna da lei Moral conforme entendida por Kant ou como produtor da paz mediante força coercitiva despótica. A regra, que deveria dar forma à vida, acaba, ao contrário, se esforçando para reduzir a forma de vida a uma regularidade identificável apenas na imposição feita pelas abstinências. $\mathrm{O}$ agir humano direcionado à felicidade de um sujeito singular torna-se incompatível com o agir pelo dever demandado pelo Direito que, possuindo força coercitiva coletiva, passa a impedir exatamente aquilo para que ele foi concebido a promover.

\footnotetext{
${ }^{4}$ Sou bem atento às possibilidades de anacronismo ao designar termos como "vontade" para significar termos técnicos da linguagem filosófica grega (ver O'Brien: Modern philosophy and platonic ethics). Entretanto, para tratar vontade e boulesthai como intercambiáveis em Aristóteles recorro à análise de T. Irwin (Who discovery the will?) em que é apresentada consistente exegese identificando boulesthai em Aristóteles e voluntas em Tomás de Aquino.
} 
Por isso MacIntyre (2006, p. 156 et seq.), retomando argumentação de Santo Tomás de Aquino, defende que um dilema moral existe sempre que se considera que há uma única resposta correta ou pelo menos que uma das respostas válidas é muito melhor do que qualquer outra. A tese do filósofo escocês se fundamenta na concepção de que, em um debate racional, uma resposta claramente superior às outras irá emergir, e o consenso que esta resposta demandará resolverá o dilema moral.

Contudo, as diversas teorias éticas, formas de vida e propostas de regimes de governo são uma marca da liberdade humana, não de erro. Assim, dilemas morais decorrem da vontade de imposição de uma doutrina Moral sobre as outras. Seja por intermédio da força violenta ou, como é o caso de MacIntyre, por meio da pretensa força excludente do melhor argumento. Este é o caso do antagonismo de doutrinas morais sobre qual é o modo correto de distribuição de recursos escassos em um Estado, sobre como o direito penal deve se reger ou sobre qual é o limite do uso da propriedade privada.

Defende-se aqui que, entendidos assim, dilemas são decorrentes do estreitamento ético de uma doutrina Moral, produto da noção de agregação de pessoas comunitariamente. Todavia, se a questão sobre a melhor maneira de se seguir uma regra for proposta pela Ética, então não há possibilidade de dilema. Existem dilemas Morais, mas questões Éticas. Pois uma Comunidade se vincula por conta dos valores morais compartilhados entre os membros do grupo, e a moral de um grupo já oferece de antemão a resposta sobre o que é a coisa certa a se fazer. Mas em uma Sociedade - e uma democracia só pode ser fruto de uma associação de pessoas - não há a necessidade do endosso universal de valores morais, entre sócios é suficiente o respeito ético pelo que não é razoavelmente rejeitável.

"Indivíduos possuem direitos, e há coisas que nenhuma pessoa ou grupo pode fazer a eles (sem violar seus direitos). Tão fortes e amplos são estes direitos que eles levantam a questão do que, se é que alguma coisa, o Estado e seus oficiais podem fazer." (NOZICK, 1974, p. IX). Estas são as frases com as quais Robert Nozick começa seu Anarchy, state, and utopia. À primeira vista, tais afirmações se apresentam como uma petição de princípio, pois não é oferecido nenhum argumento para a afirmação de que indivíduos possuem direitos. Entretanto, estas são condições sem as quais não se pode falar em Direito e, portanto, “indivíduos possuem direitos" é a premissa que torna válido se falar em juridicidade.

Assim, considerando que o Direito constitui um elemento normativo para que indivíduos possam promover suas formas de vida em sociedade, será útil avaliar os argumentos de Nozick na terceira parte de sua obra mais famosa. Ali o autor americano 
apresenta o conceito de Estrutura [framework] e os de instrumentos de Design e de Filtragem [design devices e filter devices] (1974, p. 307 et seq.). Quando compreendido como instrumento de estabilização e previsibilidade de relações sociais, o Direito se enquadra no que Nozick nomeia como Estrutura, um conjunto de regras concebidas com a pretensão de que diversos estilos de vida possam ser vividos e diferentes concepções do bem possam ser conjuntamente buscadas. Porém, o elemento fundamental do nosso problema consiste em "[não haver] razão para se pensar que há uma comunidade que irá servir como ideal para todas as pessoas e muitas razões para se pensar que não há [tal comunidade]" (NOZICK, 1974, p. 310). Assim, se for pensado como a solução de um dilema moral e, portanto, demandando uma resposta determinada que seja necessariamente melhor do que todas as demais, o Direito terá de lidar com problemas que não é capaz de solucionar. Mas, quando pensado como uma questão Ética, o Direito já não demanda uma única resposta correta determinada, ao invés, ele buscaria apenas eliminar as opções razoavelmente rejeitáveis.

O ponto que se busca destacar aqui é que o modelo de Estruturas permite a concepção de comunidades promotoras de estilos de vida em concordância com uma determinada doutrina Moral. E qualquer que seja o bem comum de uma dada comunidade, ele é incapaz de interagir com as doutrinas Morais de outras comunidades sem que as diferenças nas doutrinas gerem atrito decorrente de dilemas Morais. Pois:

\footnotetext{
Instrumentos de design constroem algo (ou sua descrição) por meio de algum procedimento que não envolve necessariamente descrições de construção de outras de seu tipo. O resultado do processo é um objeto. No caso de sociedades, o resultado do processo de design é uma descrição de uma sociedade, obtida por pessoas (ou uma pessoa) sentando e pensando sobre o que seria a melhor sociedade. Após decidir, eles passam a estabelecer todas as coisas dentro deste modelo. (NOZICK, 1974, p. 313).
}

Logo, mesmo teorias Éticas que se coloquem a determinar um bem comum que sirva de parâmetro para todas as decisões éticas, políticas e sociais estarão sujeitas aos problemas decorrentes de doutrinas Morais. Nem toda teoria Ética é capaz de propor questões éticas ao invés de soluções para dilemas Morais. É o caso, por exemplo, do Libertarianismo, que com Nozick sugere o seguinte processo de filtragem:

Instrumentos de filtragem envolvem um processo que elimina (filtra) muitas opções de um leque enorme de alternativas. As duas determinantes chaves do(s) resultado(s) finais são a natureza particular do processo de filtragem (e contra quais qualidades ela decide) e a natureza particular da gama de alternativas sobre as quais ele opera (e como esta gama é gerada). Processos de filtragem são especialmente apropriados 
para designers possuindo conhecimento limitado e que não sabem precisamente a natureza do desejado produto final. Pois o processo permite aos designers utilizar seu conhecimento de condições específicas que eles não querem que sejam violadas ao judiciosamente construir um filtro para rejeitar os violadores. (NOZICK, 1974, p. $313)$.

É por isso que mesmo um processo de filtragem, como propõe Nozick, é insuficiente para um Direito promotor de potência social e fundamentado em Justiça. Pois teorias que proponham questões Éticas indicando que um dado agente precisa escolher entre uma gama de opções disponíveis não propõe uma questão Ética, mas um dilema Moral. Um dilema Moral é constituído silogisticamente, e as doutrinas conflitantes se estabelecem como premissas maiores que condicionam o escopo das conclusões. Enquanto questões éticas, sendo modais e partindo da singularidade do caso concreto, proporcionam inferências matérias fortes e muito mais apropriadas do que um dilema Moral sequer pode ter pretensão de alcançar.

Amartya Sen dedica um grande esforço para demonstrar que várias fundamentações podem sobreviver ao debate e escrutínio como racionais e que não é necessário nem suficiente que uma razão emerja soberana perante as demais. ${ }^{5} \mathrm{O}$ foco do argumento do pensador indiano é a responsabilidade decorrente da assimetria de poder existente em vários âmbitos de uma sociedade. Por exemplo, "nós possuímos responsabilidade para com animais precisamente por conta da assimetria entre nós, não por causa de qualquer simetria que nos leva à necessidade para cooperação" (SEN, 2010, p. 205). Esse exemplo é oferecido e referenciado a Gauthama Buda no Sutta-Nipata, onde Buda faz a analogia dessa responsabilidade com a de uma mãe para com seu filho. A responsabilidade não se refere, nesse argumento, a qualquer vínculo afetivo maternal. Antes, o fundamento é o reconhecimento, por parte da mãe, de que ela é capaz de influenciar a vida do filho de um modo que o filho não é capaz de fazer com a própria vida por seus próprios meios. Não é preciso invocar nenhum argumento apontando para um benefício mútuo, seja real ou imaginado.

Para o entendimento da esfera social que temos buscado fundamentar, essa responsabilidade pode ser compreendida por ser razoavelmente rejeitável que alguém não intervenha em uma situação injusta que possa influenciar para suprimir a injustiça identificada. E como "fazer mal a alguém é o mesmo que cometer uma injustiça" (Criton 49c), qualquer ação jurídica que não seja capaz de demonstrar a justiça produzida será uma

\footnotetext{
${ }^{5}$ Sen (2010, cap. 9): "Plurality of impartial reasons".
} 
coerção despótica por invocar uma autoridade sem ter atendido à responsabilidade decorrente da assimetria.

Dessa maneira, a responsabilidade de se seguir uma regra é uma condição sem a qual não há o status normativo produtor da autoridade decorrente de direitos em uma democracia. Pois, sem responsabilidade, direitos e privilégios tornam-se indistinguíveis. E privilégios irresponsáveis são injustiças que todo cidadão democrático tem razão para rejeitar.

\section{LIBERDADE, O BEM SOCIAL DA MODERNIDADE}

A partir da modernidade, há um elemento ético que pode ser invocado como fundamento legitimador de praticamente qualquer argumento no debate público. "Entre todos os valores éticos que intentam vingar na sociedade moderna, e, ao vingar, tornam-se hegemônicos, apenas um deles mostra-se apto a caracterizar o ordenamento institucional da sociedade de modo efetivamente duradouro: a liberdade no sentido da autonomia do indivíduo." (HONNETH, 2015, p. 34). A potência da liberdade como razão legitimadora é tão grande que até mesmo posições absurdas, como a "liberdade de se expressar nazista", tentam se valer dela e, apesar de ignorado seu aspecto ético, conseguem gerar eficácia social quando em um contexto de anomia. Assim a possibilidade, propiciada pela liberdade, de a autonomia do indivíduo conferir potência [dynamis] ao sistema jurídico constitui a faca democrática de dois gumes que justifica o argumento da perigosa proximidade entre Democracia e Tirania no livro VIII da República. Pois, ao dinamizá-los, a Liberdade restitui o estatuto ontológico da potência aos sistemas sociais que, de outro modo, se concebem apenas em suas efetivas atualidades autoproduzidas. “A liberdade transcendente não é, contudo, apenas uma 'espécie' particular de fundamento, mas a fonte do fundamento em geral. Liberdade para o fundamento.” (HEIDEGGER, 1988, p. 87). Por isso, buscar-se-á tematizar a liberdade para que sua hegemonia só possa valer quando apropriada eticamente.

A declaração com a qual Nozick abre seu Anarquia, estado e utopia ${ }^{6}$ traduz perfeitamente o insight hobbesiano que fundamenta o Direito moderno compreendido como mediação entre vontades antagônicas. Pois, quando no Leviatã é afirmado que "Liberdade significa, em sentido próprio, a ausência de oposição (entendendo por oposição os

\footnotetext{
${ }^{6}$ Individuals have rights, and there are rights no person or group may do to them (without violating their rights). So strong and far-reaching are these rights that they raise the question of what, if anything, the state and its officials may do.
} 
impedimentos externos ao movimento)" (HOBBES, 2014, p. 179), é oferecida uma ideia que define apenas negativamente a autodeterminação individual. Nessa concepção não é permitido ao Estado determinar previamente quais as formas de vida um sujeito pode escolher para si. Perfeitamente sustentada pelo argumento de Locke, de que não é possível obrigar alguém a acreditar naquilo de que ele não tenha convicção, a ideia de liberdade negativa qualifica a rejeição de um Bem Comum como fundamento da atividade jurídica.

A questão passa a ser então a autodeterminação intermediada pela autonomia individual. Uma inferência que parece ser possível na perspectiva hobbesiana é a identidade entre autodeterminação e ser guiado por elementos de sua própria natureza. Nessa concepção, o que é mais próprio à natureza de alguém se manifesta como a regularidade comportamental com finalidade a manutenção da homeostasis do organismo. Afinal, para Hobbes, a vida feliz só pode ser aquela em que se termina velho morrendo na sua própria cama.

Assim, concebida apenas em sua esfera negativa, estar livre do Direito significa que o indivíduo estará abandonado à margem da comunidade se não compartilha do Bem Comum desta. "Em tal ordenamento jurídico [da liberdade negativa], aos sujeitos não é dada a oportunidade de conjuntamente verificar e renovar sua anuência às medidas de Estado, por estarem incluídos no processo de criação e revisão dos princípios jurídicos." (HONNETH, 2015, p. 55). Dessa maneira, ao indivíduo que possua apenas a liberdade negativa só resta a posição de bandido ou abandonado, sendo-lhe negado o status de cidadão. Portanto,

Partir de uma liberdade apenas negativa não permite que os cidadãos do Estado sejam apreendidos como autores e renovadores de seus próprios princípios jurídicos; para isso seria necessário que, na aspiração à liberdade pelo indivíduo, em termos conceituais, se justificasse um ponto de vista adicional e de grau mais elevado que lhe atribuísse um interesse na cooperação com todos os demais. (HONNETH, 2015, p. 55-56).

Por isso, o Direito não pode se resumir a tornar a pessoa livre do Estado, antes, da liberdade jurídica é demandado um aspecto positivo tão importante quanto o negativo. Além de livrar as pessoas das imposições do Bem Comum, o Direito tem o dever de deixar o indivíduo livre para buscar seu bem apropriado.

Todas as insuficiências reveladas pela ideia de liberdade negativa remetem, em última instância, ao fato de ela cessar antes do limiar legítimo da autodeterminação individual. Para se conceber um tipo de liberdade que contivesse um elemento de autodeterminação seria necessário apreender também o objetivo do agir como um rebento da liberdade: o que o individuo realiza quando age "livremente", poderia ser 
visto como resultado de uma determinação, que ele próprio realiza para si. (HONNETH, 2015, p. 57).

Logo, o elemento ético que qualifica a liberdade como razão legitimadora da ação social será reconhecido na regra constitutiva da forma de vida do cidadão. Todavia,

\begin{abstract}
a liberdade negativa é elemento originário e indispensável da autoconcepção moral da modernidade; nela se expressa a ideia de que o indivíduo deve desfrutar do direito de agir sem restrição externa e sem depender de coerção para provar os motivos de 'seu bel-prazer' enquanto não violar os mesmos direitos de seus concidadãos. (HONNETH, 2015, p. 58).
\end{abstract}

E, por isso, a liberdade negativa demanda a compreensão que ela só pode se dar em um âmbito intersubjetivo, em uma sociedade que reconheça cada pessoa em sua singularidade mais própria. E, ao mesmo tempo, demanda do indivíduo a responsabilidade decorrente de saber que não se é possível seguir uma regra de modo solipsista, e que seguir uma regra implica impor a si mesmo restrições. Portanto, desfrutar da liberdade negativa só é intitulamento daquela pessoa que reconhece no outro um sócio digno de respeito.

Ao contrário da liberdade negativa, que só observa a força coercitiva do Direito a fím de estabelecer limites para coerção, observando apenas a vontade mais própria do agente, uma vontade reflexiva se relaciona com a força coercitiva do Direito por meio da tensão entre ações autônomas e heterônomas. Uma ação heterônoma consiste no agir cujo fim almejado não é estabelecido pelo próprio agente, mas por uma determinação prévia à ação, como a letra da lei legislada ou a pretensa intenção do legislador. Já uma ação jurídica autônoma consiste no autor pôr em uso a lei por meio da leitura e, em sua apropriação dela, conceder-lhe eficácia social.

$\mathrm{O}$ elemento fundamental da liberdade reflexiva consiste em, enquanto sujeitos racionais, não sermos obrigados por uma lei, mas pela nossa compreensão da lei. Desse modo, a liberdade reflexiva seria aquela na qual a autonomia do sujeito consiste na apropriação de uma regra por uma pessoa. Assim, a heteronomia do Direito, a imposição de modos de conduta por conta de um processo legislativo alheio ao indivíduo, só deve ser observada se puder ser tornada própria, autônoma, pelo autor que é o titular do Direito.

Para a compreensão dessa dimensão da liberdade, contudo, é importante observar as mudanças provocadas pela teoria filosófica, que passa a demandar a intersubjetividade e não mais meramente a autonomia subjetiva, como espaço de fundamentação e apropriação de regras. 
O que até então devia ser o esforço de um sujeito solitário, autorreferente, passa a ser interpretado mediante uma viragem teórico-linguística, como produto comunicativo dos membros de uma comunidade linguística: o indivíduo se vê forçado por pressuposições que atuam por trás da linguagem, de modo que a si mesmo ele concebe como parte numa conversa em que todos os demais têm de se respeitar como pessoas autônomas. (HONNETH, 2015, p. 69).

Deste modo, a possibilidade de autorrealização almejada pela liberdade é, por meio de sua reflexão intersubjetiva, convertida em produto processualmente estabelecido por interlocutores que devem estabelecer fins que não sejam razoavelmente rejeitáveis. Todavia, quando esse produto se vincula ao Direito por meio de uma doutrina Moral que entenda a justiça como resultado de um processo, "a autodeterminação individual é transferida para os graus superiores do ordenamento social, em que é concebida como procedimento de uma formação da vontade comum na qual os cidadãos, em condições iguais, deliberam sobre os princípios de um ordenamento social que lhes pareça “justo"” (HONNETH, 2015, p. 73).

Assim, se desvinculados das regras constitutivas das formas de vida de cidadãos singulares, os modelos de liberdade reflexiva ainda não indicaram "as condições sociais que possibilitariam o exercício da liberdade em cada caso já como componentes da liberdade" (HONNETH, 2015, p. 80). Portanto, a liberdade reflexiva apropriada deve poder recorrer à potência institucional produzida pelo Direito em uma democracia. E, por meio da mediação ética entre o autor e sua concepção da regra, responder

qual ontologia e qual ética corresponderão a uma vida que, no uso, se constitui como inseparável de sua forma? A tentativa de responder a essa pergunta exigirá necessariamente um confronto com o paradigma ontológico operativo em cujo quadro a liturgia, por um processo secular, acabou por aprisionar a ética e a política do Ocidente. (AGAMBEN, 2014, p. 147).

Ao relacionar justiça e liberdade, é sugerido que seria "essa ampliação institucional do conceito de liberdade que servirá de diretriz a [um outro] conceito de liberdade, que é social. Segundo essa concepção, a ideia de liberdade reflexiva não se deixa desdobrar sem incluir as formas institucionais que possibilitam o seu exercício" (HONNETH, 2015, p. 80). O capability approach de Sen se apresenta como uma proposta de resposta, tendo em vista que a abordagem de capacidades foca na vida humana. "Decerto, ele propõe uma séria ruptura com a concentração nos meios de se viver [entendidos como recursos ou bens básicos a serem distribuídos] para focar nas oportunidades efetivas do viver." (SEN, 2010, p. 233). Assim, o bem apropriado pelo sujeito ao determinar a regra de sua forma de vida tem destaque por meio da distinção entre efetivo bem-estar e livre bem-estar e efetiva agência e livre agência 
humana proposta por Sen. Pois "o foco da abordagem de capacidades é, portanto, não apenas no que uma pessoa efetivamente acaba fazendo, mas também em o que ela é de fato apta a fazer, tendo ou não ela escolhido fazer uso daquela oportunidade” (SEN, 2010, p. 235).

\section{JUSTIÇA É FORMA DE VIDA QUE PRODUZ O BEM DO OUTRO}

Para o exercício da Liberdade em uma Democracia é de vital importância que a pessoa possa se dedicar à busca de um bem apropriado. A determinação desse bem certamente variará de acordo com a propriedade de cada pessoa, mas a capacidade para realizar a busca é um elemento necessário. Nesse sentido, é importante a qualificação da pobreza como debilidade de capacidade oferecida pelo criador do IDH, Amartya Sem, pois uma democracia demanda uma concepção da justiça que permita o melhoramento das vidas das pessoas. E se a melhor vida pode ser concebida como aquela em que o sujeito tenha capacidade de buscar seu bem apropriado, então a redução da pobreza consiste em promoção da justiça.

De pronto é preciso reconhecer que "a identificação da pobreza com baixa renda é bem estabelecida, mas já existe, a essa altura, uma literatura substancial sobre sua inadequação" (SEN, 2010, p. 254). Assim, o que se busca é ressaltar os elementos que permitam a efetivação da liberdade social. Aponta-se aqui para a característica promoção da liberdade decorrente da justiça. Nesse caso a liberdade promovida é uma que promove a capacidade das pessoas em perseguir o bem que lhes seja apropriado. A liberdade social, em sua eticidade, consiste no gozo de autoridade fundamentada na responsabilidade de se suprimirem as injustiças que se tenha identificado. Responsabilidade é atribuída em relação ao fim almejado da ação ou aos meios empregados para se alcançar esse fim. E no caso de uma injustiça ter sido identificada, a definição de um fim qualquer à ação que não seja a supressão dessa injustiça poderá ser razoavelmente refutável.

Assim, a justiça precisa reconhecer heterogeneidades pessoais, diversidades no ambiente físico e social e diferenças em perspectivas relacionais para que o bem promovido seja o do outro e não uma mera projeção do bem do agente que, por acaso, venha a coincidir com o do afetado pela ação. Nesse sentido, "avaliação refletida demanda raciocínio sobre importância relativa e não apenas contabilização. Isto é um exercício no qual estamos constantemente engajados" (SEN, 2010, p. 241). Por isso, um fundacionismo avaliativo dificulta a proposição de questões éticas, por apresentar essas questões como dilemas Morais. Logo, apenas a demarcação de que a justiça é fazer o bem de um outro não será suficiente, é 
preciso lembrar que justiça é uma excelência. Mas felizmente é uma excelência alcançável de diversos modos.

Para demonstrar, concebamos a questão ética sobre ajudar um homem negro ou uma mulher branca. Na compreensão que proponho de uma questão ética, os meios possíveis de serem empregados constituem a premissa da qual a ação justa deve originar-se. Com isso, a forma de vida do agente em questão condiciona como ele pode, excelentemente, influenciar em uma dada situação. Conhecer as próprias capacidades permite aplicá-las a situações em que elas causarão maior benefício. Esta é a premissa platônica de que o que deve ser feito será feito do modo mais excelente.

Assim, enquanto doutrinas Morais podem estabelecer de antemão as respostas, um sujeito ético observará onde sua ação pode causar o maior benefício a um outro.

\begin{abstract}
Para usar uma distinção medieval, não somos apenas "pacientes" cujas necessidades merecem consideração, mas também "agentes" com liberdade para decidir nossos próprios interesses e necessidades. $\mathrm{O}$ significado de nossas vidas não pode ser posto na caixinha de nossos padrões de vida, ou satisfação de necessidades. As necessidades manifestas do paciente, importante como elas são, não podem eclipsar a relevância momentânea dos valores razoáveis do agente. (SEN, 2010, p. 252).
\end{abstract}

Com isso queremos dizer que a responsabilidade do sujeito ético não é absoluta. Ela é sempre relativa às capacidades do agente e é a assimetria de capacidades que vincula normativamente um agente à supressão da injustiça. Assim, mesmo em uma sociedade com características marcadamente machistas, uma mulher branca possui a responsabilidade de suprimir o racismo que afeta um homem negro. Do mesmo modo, um homem negro possui a responsabilidade de evitar, dentro de suas capacidades, assédios machistas à mulher branca. Mantemos o exemplo simples apenas por questão de clareza. Contudo, o que queremos destacar aqui é que as injustiças que somos capazes de suprimir não se manifestam como problemas identificados atomicamente, mas como paradigmas holisticamente determinados. E, portanto,

Pode haver alguma "combinação" de desvantagens entre diferentes fonts de privação, e isto pode ser uma importante consideração crítica na compreensão da pobreza e na produção de políticas públicas para lidar com ela. [...] Assim, pobreza real (em termos de privação de capacidade) pode facilmente ser muito mais intensa do que pode-se deduzir dos dados coletados. Isto pode ser um interesse crucial na abordagem de ações públicas para dar assistência aos idosos e outros grupos com dificuldade de conversão de bens em capacidade em adição à sua baixa renda. (SEN, 2010, p. 256-257). 
Desse modo, a demarcação de que nós, enquanto sujeitos singulares, conseguimos ajudar pessoas e não solucionar todos os problemas de alguém é de suma importância para uma compreensão da justiça e da democracia. Pois, ao se demarcar que a justiça não se identifica com o produto procedimental de uma dada operação social, mas com a forma de vida que nos capacita à excelência que melhora gradativamente a sociedade, tiramos de nossos ombros o fardo de tornar a sociedade perfeita, reconhecendo que algo em estado de potência possui tanta realidade quanto o ato puro.

Assim, a tese que remete a Hegel, na qual somente quando eu reconheço no outro um cidadão com autoridade social democrática poderei também reclamar essa autoridade democrática, se manifesta de modo bastante claro. Para o sujeito social,

quanto mais forte for a impressão de que seus objetivos são apoiados e mesmo assumidos por aqueles com quem tem uma interação frequente, mais propensos estarão a perceber seu ambiente como espaço de expansão de sua própria personalidade. Para seres dependentes de interações com seus iguais, a experiência de tal interação não coercitiva entre a pessoa e seu ambiente intersubjetivo representa o padrão de toda a liberdade individual. (HONNETH, 2015, p. 115).

Desse modo, a supressão da pobreza por meio da promoção das capacidades deve, para ter sucesso, conferir ao indivíduo a liberdade de determinar seu bem apropriado. E, em oposição à noção de que Justiça se identifique com manutenção da ordem social, é preciso perguntar como as coisas estão indo e se elas podem ser melhoradas.

A liberdade social constitui a capacidade de o indivíduo se determinar como uma subjetividade. Pois um indivíduo é definido como a parte mínima de um dado conjunto e, portanto, mesmo alguém que apenas componha uma massa populacional sem voz ativa poderá ser tomado como indivíduo. Entretanto, uma subjetividade só pode se constituir pelo posicionamento enquanto sujeito e ator social. Desse modo, se o Direito e a Política direcionam sua atenção somente ao efetivo bem-estar e às perlocuções geradas pela agência efetiva, a liberdade inerente à subjetividade é suprimida, e os sujeitos se reduzem a meros indivíduos, números em um dado populacional. Porém se a importância das vidas humanas reside não meramente em nosso padrão de vida e atenção a necessidades, mas também na Liberdade da qual gozamos, então a ideia da promoção de bem-estar social deve ser reformulada de acordo. Afinal, "a perspectiva da abordagem de capacidades aponta para a relevância central das desigualdades de capacidades na avaliação de disparidades sociais, mas não propõe, por si mesma, qualquer fórmula específica para decisões de políticas governamentais" (SEN, 2010, p. 232). 
A tese defendida neste trabalho trata o Direito como fonte de eficácia social à qual um sujeito pode recorrer, em detrimento da violência, para se corrigir uma injustiça. $\mathrm{O}$ recurso ao Direito demanda, portanto, razões, o que somente uma subjetividade é capaz de oferecer. Afinal, é ao se assumir a posição de sujeito que se dá vida a uma linguagem. Desse modo, pelo Direito um sujeito pode reivindicar viver de certa forma em uma democracia. "Viver de acordo com uma forma implica, sem dúvida, segundo um significado frequente do termo forma no latim medieval, uma relação exemplar com outros e, mesmo assim, não é simplesmente sinônimo de exemplum." (AGAMBEN, 2014, p. 110). É importante que uma forma de vida não seja meramente um exemplum, pois um exemplum está mais próximo de uma pretensa solução de um dilema moral do que uma proposta para vida ética. "Mas é decisivo que a forma de vida não coincida nem com um sistema normativo nem com um corpus de doutrinas. Ela é um terceiro entre a doutrina e a lei, entre a regra e o dogma, e é só a partir da consciência dessa especificidade que sua definição poderá tornar-se possível." (AGAMBEN, 2014, p. 109).

No contexto de um Direito democrático, esse terceiro se manifesta na liberdade que nos condiciona à compreensão de uma regra. Pois a apropriação da regra, produto dessa compreensão, se dá como efetivação de uma vida em comum. "O sintagma franciscano regula et vitae não significa uma confusão entre regra e vida, mas a neutralização e a transformação de ambas numa 'forma-de-vida'." (AGAMBEN, 2014, p. 113). Aqui se mira na vida refletida que vale a pena ser vivida e que se dá como exercício da liberdade social, pois a própria formação da subjetividade demanda a vida em comum com outras subjetividades que sejam reconhecidas enquanto pessoas e não somente como indivíduos.

O Direito, portanto, converte comunidades em uma sociedade exatamente ao conferir à diversidade fragmentada de projetos de vida individuais uma forma democrática. Só uma vida que participe da ideia de liberdade e que livremente determine seu bem mais próprio pode ser qualificada como democrática. "Não se trata tanto de aplicar uma forma (ou uma norma) à vida, mas de vivere de acordo com aquela forma, ou seja, de uma vida que, no ato de a seguir, ela própria se torna forma, coincide com ela.” (AGAMBEN 2014, p. 105). É na harmonização entre o bem do todo da sophrosyne, do bem apropriado sapientemente pelo sujeito e da liberdade de se promover esses bens que a Justiça se manifesta como dikaiosyne, como um modo excelente de viver. Muito além da mera reformulação dogmática do Direito, 
[...] o que continuava não pensado era precisamente a aspiração originária que havia levado os movimentos [sociais] a reivindicar uma vida e não uma regra, uma forma vitae e não um sistema mais ou menos coerente de ideias e doutrinas - ou, mais precisamente, a propor não uma nova exegese do texto sagrado [direito positivo] mas sua pura e simples identificação com a vida, como se eles não quisessem ler e interpretar o Evangelho [a Constituição], mas apenas vivê-los. (AGAMBEN, 2014, p. 99-100).

\section{REFERÊNCIAS}

AGAMBEN, Giorgio. Profanações. São Paulo: Boitempo: 2007.

AGAMBEN, Giorgio. Altíssima pobreza. São Paulo: Boitempo, 2014.

ARISTÓTELES. Metafísica. Giovanni Reale (ed.). Tradução brasileira Marcelo Perini. São Paulo: Loyola, 2005.

BRANDOM, Robert B. Making it explicit: reasoning, representing \& discursive commitment. Cambridge: Havard University Press, 1994.

BRANDOM, Robert B. Reason in philosophy: Animating Ideas. Cambridge: Havard University Press, 2009.

CORTINA, Adela; MARTINEZ, Emílio. Ética. São Paulo: Loyola, 2013.

FEYERABEND, Paul K. Against method. 3rd. ed. Londres: New York: Verso, 1993.

HEIDEGGER, Martin. A essência do fundamento. Lisboa: Edições 70, 1988.

HOBBES, Thomas. Leviatã ou matéria, forma e poder de uma república eclesiástica e civil. São Paulo: Martins Fontes, 2014.

HONNETH, Axel. O Direito da liberdade. São Paulo: Martins Fontes, 2015.

MACINTYRE, Alasdair. Justiça de quem? Qual racionalidade? São Paulo: Loyola, 1991.

MACINTYRE, Alasdair. Ethics and politics. Selected essays, v. 2. New York: Cambridge University Press, 2006.

NOZICK, Robert. Anarchy, state and utopia. New York: Basic Books, 1974.

SCANLON JR, Thomas M. What we owe to each other. Cambridge: Harvard University Press 1998.

SEN, Amartya. The idea of justice. Cambridge: Harvard University Press, 2010. 